\title{
Morphology of the Pachytene Chromosomes of Impatiens balsamina L. var. bicolor
}

\author{
S.S. Raghuranshi and Savita Mahajan \\ Cytogenetics and Plant Breeding Laboratory, Department of Botany, \\ Lucknow University, Lucknow-226007, India
}

Accepted February 13, 1983

Pachytene analysis has been proved to be one of the ground works in cytogenetic and evolutionary studies in species and species hybrids after the cytological studies of McClintock (1929) in Zea mays and now have been extended to many other species of plants. Venkateswarlu (1962) has fully recognised the usefulness of such a study especially in the problem of chromosome aberrations and in the proper understanding of the degree of chromosome homology. Accurate study of structure of chromosomes at pachytene gives details of the linear differentiation of chromosomes, namely chromomeric pattern, position of centromere, location of nucleolus and the distribution of the heterochromatin. As the homologous chromosomes are paired even a small structural difference can be studied.

The present paper is concerned with the pachytene morphology of Impatiens balsamina L. (var. bicolor) chromosome complement which has $2 \mathrm{~B}$ chromosomes. Particular emphasis is placed on identification of the characteristics of each chromosome which is useful in tracing the origin of accessory chromosomes in Impatiens balsamina.

\section{Material and methods}

In Impatiens balsamina the pachytene chromosomes present much difficulty in preparation of well spread and well stained slides, so it was necessary to find a technique for suitable staining of the pachytene chromosomes. The following technique proved suitable for study of the pachytene chromosomes in the present material-anthers from young flower buds were fixed randomly in $1: 3$ acetic alcohol (Carnoy's fluid) fortified with iron and then the anthers were kept in the fixative from 58 to 72 hours at room temperature, black colour of the anthers was good indication of proper mordanting. After fixation the anthers were transferred to $70 \%$ ethyl alcohol and stored at low temperature in a refrigerator.

The anthers were squashed in $2 \%$ acetocarmine. Alternate heating and squashing aided in the differentiation and flattening of chromosomes. Temporary slides were sealed with wax for study. In a single PMC it was difficult to trace from end to end all the pachytene bivalents. PMCs with excellent spreading and differentiation of pachytene bivalents at mid pachytene stage were selected for study, as this was the best stage for accurate identification of morphological details and measurement of chromosomes. 
Drawings were made with the help of prism type camera lucida at bench level using $10 \times$ eye piece and $100 \times$ oil immersion objective.

The length of chromosomes, position of centromere, the number, size and distribution of chromomeres were drawn and measured in microns. An idiogram was drawn with long arms on the lower side and short arms on upper side. The chromosomes were numbered as was done by Barton (1950) who had followed the method of numbering adopted by McClintock (1929) in Zea mays. According to this the longest chromosome was numbered as chromosome one and the successive ones 2-3 etc. Length and arm ratios (length of short arm/long arm) was measured for individual chromosomes separately. Identification of individual chromosomes was made as follows-median arm ratio 1.00 to 0.80 , submedian arm ratio 0.79 to 0.40 and subterminal arm ratio $0.39-0.10$.

\section{Observations}

The pachytene bivalents displayed the poorly differentiated type where the chromosomes stained uniformly throughout their length and exhibited a certain degree of clumping. However, differentiated and well spread pachytene configurations were observed occasionally in the PMCs which were selected for this pachytene analysis. The homologous chromosome pairing was found to be complete and apparently normal. The darkly stained regions flanking the centromere are the chromatic regions and the distal regions are the achromatic regions.

The data of total length (including centromere), length of long and short arm, relative length, arm ratio, chromatic and achromatic lengths obtained for each of the eight bivalents $(7 \mathrm{~A}+1 \mathrm{~B})$ are given in Table 1 . The photomicrographs along with the line drawings of 8 bivalents (7A and $1 \mathrm{~B}$ ) are given in figures $1 \mathrm{~A}$ to $8 \mathrm{~A}$ and $1 \mathrm{~B}$ to $8 \mathrm{~B}$ respectively and an idiogram of these chromosomes is given in Fig. 9.

The characters of $7 \mathrm{~A}$ bivalents and the accessory bivalent at pachytene stage are described as follows:-

Chromosome. 1.-Longest of the complement with an average length of 56.41 $\mu \mathrm{m}$ has a median centromere and an arm ratio of $0.95: 1$. In the long arm there are 3 chromomeres while in the short arm there are 6 chromomeres adjacent to the centromere followed by achromatic segments.

Chromosome. 2-Average length $51.28 \mu \mathrm{m}$ with an arm ratio of 0.78 , the centromere is submedian, relative length 90.90 . In both the arms there are 3-3 chromomeres flanking the centromere and the rest of the portion consists of achromatic regions.

Chromosome. 3-Average length $43.59 \mu \mathrm{m}$ with an arm ratio of 0.74 . This chromosome has the highest amount of chromatic segment than any other chromosome of the complement, relative length 77.27 , centromere is submedian, seven chromomeres are present in the short arm and 9 in the long arm.

Chromosome. 4-Submedian centromere with an average length of $41.66 \mu \mathrm{m}$, arm ratio 0.71 , relative length 73.87 . Three chromomeres are present in the short arm and two in the long arm surrounding the centromere and rest of the part of the arms is achromatic. 
Chromosome. 5-This chromosome is distinguished from the other chromosomes by the attachment of its long arm to the nucleolus by a deeply staining nucleolar organizing body. Nucleolar organizing body is terminal to the long arm situated at a little distance from the nucleolus. The chromosome is nearly median

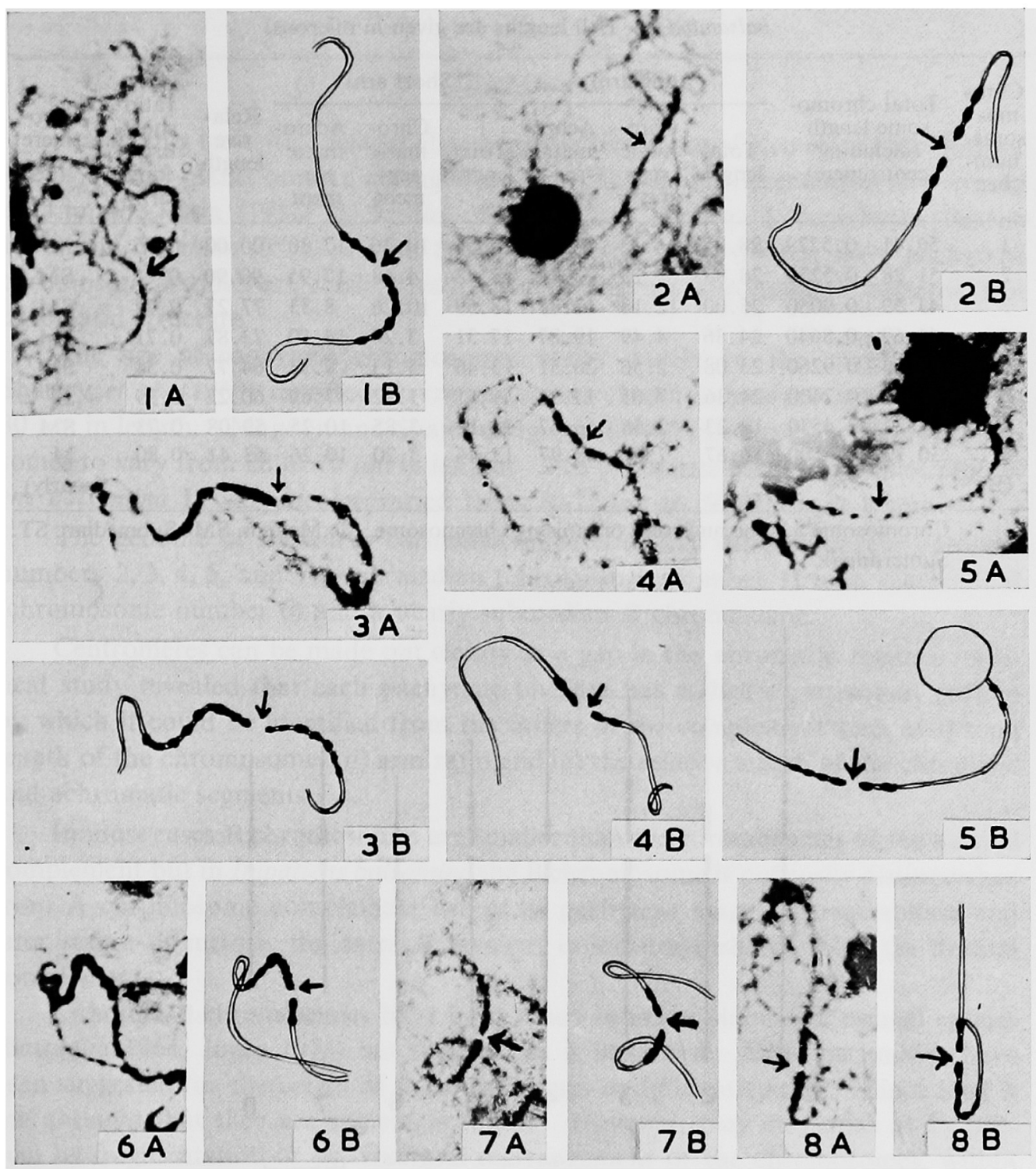

Figs. 1-8. Eight pachytene bivalents in B chromosome carrier cells of Impatiens balsamina. 1A8A, microphotographs of pachytene bivalents arranged in decreasing order of length. 1B-8B, line drawings of the same.

with an average length of $36.54 \mu \mathrm{m}$, arm ratio is 0.58 and relative length is 64.77 . In the short arm there are four chromomeres and in long arm there are 2 chromomeres.

Chromosome. 6-This is the only subterminal chromosome with an arm ratio 
of 0.39 , average length is $33.97 \mu \mathrm{m}$ and relative length is 60.22 . Two chromomeres are present in the short arm and five in the long arm adjacent to the centromere.

Chromosome. 7-Average length $33.33 \mu \mathrm{m}$, centromere submedian, arm ratio 0.73 and relavtie length is 59.08 . Two chromomeres are present in short arm and

Table 1. Average values from each of the 8 chromosomes $(7 \mathrm{~A}+1 \mathrm{~B})$ of Impatiens balsamina $\mathrm{L}$. (All lengths are given in microns)

\begin{tabular}{|c|c|c|c|c|c|c|c|c|c|c|}
\hline \multirow{2}{*}{$\begin{array}{l}\text { Chro- } \\
\text { mo- } \\
\text { some } \\
\text { num- } \\
\text { ber }\end{array}$} & \multirow[b]{2}{*}{$\begin{array}{l}\text { Total chromo- } \\
\text { some length } \\
\text { (including } \\
\text { centromere) }\end{array}$} & \multicolumn{3}{|c|}{ Long arm } & \multicolumn{3}{|c|}{ Short arm } & \multirow[b]{2}{*}{$\begin{array}{c}\text { Rela- } \\
\text { tive } \\
\text { length }\end{array}$} & \multirow{2}{*}{$\begin{array}{l}\text { Arm } \\
\text { ratio } \\
\text { short } \\
\text { arm/ } \\
\text { long } \\
\text { arm }\end{array}$} & \multirow[b]{2}{*}{$\begin{array}{r}\text { Centro- } \\
\text { mere } \\
\text { type }\end{array}$} \\
\hline & & $\begin{array}{l}\text { Total } \\
\text { length }\end{array}$ & $\begin{array}{l}\text { Chro- } \\
\text { matic } \\
\text { seg- } \\
\text { ment }\end{array}$ & $\begin{array}{l}\text { Achro- } \\
\text { matic } \\
\text { seg- } \\
\text { ment }\end{array}$ & $\begin{array}{r}\text { Total } \\
\text { length }\end{array}$ & $\begin{array}{c}\text { Chro- } \\
\text { matic } \\
\text { seg- } \\
\text { ment }\end{array}$ & $\begin{array}{l}\text { Achro- } \\
\text { matic } \\
\text { seg- } \\
\text { ment }\end{array}$ & & & \\
\hline 1 & $56.41 \pm 0.5229$ & 28.85 & 5.13 & 23.72 & 27.56 & 10.26 & 17.30 & 100.00 & 0.95 & $\mathbf{M}$ \\
\hline 2 & $51.28 \pm 0.5220$ & 28.85 & 5.13 & 23.72 & 22.43 & 4.48 & 17.95 & 90.90 & 0.78 & SM \\
\hline 3 & $43.59 \pm 0.9050$ & 25.00 & 12.18 & 12.85 & 18.59 & 10.26 & 8.33 & 77.27 & 0.74 & SM \\
\hline 4 & $41.67 \pm 0.8640$ & 24.36 & 4.49 & 19.87 & 17.31 & 3.20 & 14.10 & 73.87 & 0.71 & $\mathbf{S M}$ \\
\hline $5 *$ & $36.54 \pm 0.9260$ & 23.08 & 2.56 & 20.51 & 13.46 & 5.13 & 8.33 & 64.77 & 0.58 & SM \\
\hline 6 & $33.97 \pm 0.7400$ & 24.36 & 7.05 & 17.31 & 9.61 & 1.92 & 7.69 & 60.22 & 0.39 & ST \\
\hline 7 & $33.33 \pm 0.4530$ & 19.23 & 2.56 & 16.67 & 14.10 & 3.85 & 10.25 & 59.08 & 0.73 & $\mathbf{S M}$ \\
\hline $\begin{array}{l}8 \\
\text { (B) }\end{array}$ & $30.13 \pm 0.5500$ & 16.67 & 7.69 & 8.97 & 13.46 & 3.20 & 10.26 & 53.41 & 0.80 & $\begin{array}{c}\mathrm{M} \\
\text { (nearly) }\end{array}$ \\
\hline
\end{tabular}

* Chromosome 5 is the nucleolus organising chromosome, M: Median, SM: Submedian, ST: Subterminal.

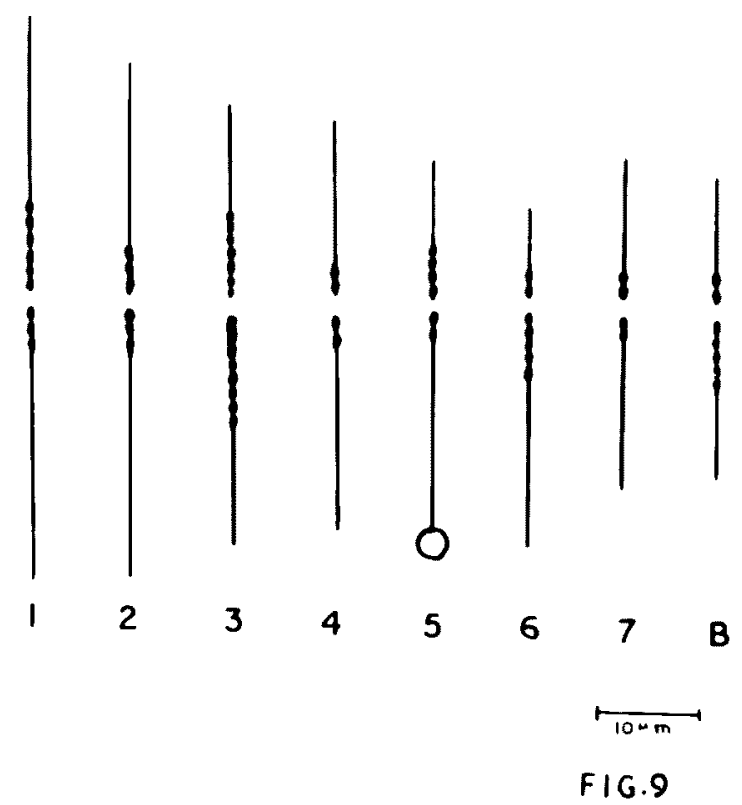

Fig. 9. Idiogram of pachytene chromosome complement of Impatiens balsamina L.

two in long arm adjacent to the centromere followed by achromatic segments.

Chromosome. 8 (B chromosome)-This is the smallest chromosome of the complement and is well distinguished from the smallest chromosome of the A complement. It has a nearly median centromere with a relative length of 53.41 and an 
average length of $30.13 \mu \mathrm{m}$. Flanking the centromere two chromomeres are present in the short arm and 5 in long arm and rest portion consists of achromatic regions.

For more accurate study of the pachytene chromosomes length of achromatic and chromatic segments was also studied. One chromosome had subterminal centromere, one had median, five had submedian and the B chromosome had a nearly median centromere.

\section{Discussion}

Few plants have well defined chromosomes like those of Zea mays (McClintock 1929). Many plants have an average degree of pachytene differentiation as observed by Lima-de-Faria (1952) in Secale. While plants such as Lycopersicon (Barton 1950) and Sorghum (Magoon and Shambulingappa 1960) do not have pachytene chromosomes which are readily resolved into distinct chromomere patterns and chromatid structure.

The size of pachytene chromosomes varies widely in the plant kingdom. Shastry et al. (1960) reported Oryza pachytene chromosomes to vary from 20 to $80 \mu \mathrm{m}$ in length. Magoon and Shambulingappa (1960) observed Sorghum chromosomes to vary from 28 to $79 \mu \mathrm{m}$ in length. The pachytene chromosomes of Impatiens balsamina L. var. bicolor varied from $30.12 \mu \mathrm{m}$ to $56.41 \mu \mathrm{m}$ in length.

The genome of Impatiens balsamina consists of five submedian (chromosome numbers $2,3,4,5$, and 7 ), one median (chromosome number 1), one subterminal (chromosome number 6) and a nearly submedian B chromosome.

Centromeres can be made out clearly as a gap in the chromatic regions. Critical study revealed that each pachytene bivalent has a distinct structural pattern by which it could be identified from the others in the complement such as i) total length of the chromosomes, ii) arm ratio and iii) the relative length of the chromatic and achromatic segments.

In most cases B chromosomes are smaller than the chromosomes of the normal complement but in Impatiens balsamina the B chromosome is not easily distinguished from A chromosome complement except at pachytene stage. At metaphase and later stages of meiosis the extra $\mathrm{B}$ bivalent is indistinguishable from the normal complement.

Although B chromosomes have been found in many plants and animal species (Battaglia 1964, Jones 1975) but their origin is unknown. Different modes have been suggested for the origin of B chromosomes in different species. Since long it was thought that they are ancient in origin. However, they may arise as by-product by fragmentation or by structural rearrangement of the chromosomes, within the normal complement. These structural alternations may involve translocations and inversions, such as Lewis (1951) has postulated that unequal distribution in translocations of heterozygotes is probable mechanism in the origin of accessory chromosomes in Clarkia elegans. Swanson (1943) assumed the presence of overlapping inversions in Tradescantia, consequent crossing over in the area of the overlap could result in the origin of accessory chromosomes.

$\mathrm{Wu}$ and $\mathrm{Pi}(1975,1978)$ postulated that the accessory chromosome of Sorghum 
nitidum is similar in structure to the short arm of the nucleolus associated chromosome which is fully chromatic thus it appears to be an isochromsome. At the pachytene stage it does not pair with any of the A chromosomes but it folds back to pair with itself and looks like a telocentric chromosome which seems to have a terminal knob distal to the centromere.

B chromosomes of Impatiens balsamina can be distinguished from rest of the chromosomes at pachytene as it has the shortest length and a nearly median centromere. Comparative analysis of $\mathbf{B}$ chromosomes and $\mathrm{A}$ chromosomes at pachytene appear to indicate some relationship with chromosome number six on the basis of chromomeric patterns. It may be possible to visualise the origin of B chromosomes from this chromosome by deletion and translocation. However, it must be mentioned that at present there does not appear to be any homology between $\mathrm{B}$ chromosomes and any A chromosome, because during meiosis Bs do not pair with any other chromosome. But the fact remains that whenever present in a PMC the Bs are two in number and are homologous thus always having a pairing partner. Under thesc circumstances even if the Bs have some homology still left with chromosome number six probably B homologous may pair with each other without giving any opportunity for pairing with chromosome number six. One can as well speculate that it is possible that this pairing relationship may be under some sort of genetic control.

\section{Acknowledgement}

Authors are thankful to the Head, Department of Botany for providing Laboratory facilities. Financial support from the Department of Science and Technology is gratefully acknowledged.

\section{Summary}

Detailed pachytene morphology of chromosomes of Impatiens balsamina L. var. bicolor with two accessory chromosomes $(2 n=14+2 B)$ has been analysed. The two $\mathrm{B}$ chromosomes always pair to form a bivalent which behaves normally during meiosis. All the chromosomes were analysed individually on the basis of total length of chromosomes, length of chromatic and achromatic segments, arm ratio and an idiogram was drawn, chromosome 5 has the nucleolar organiser in its long arm, chromosomes $2,3,4,5$ and 7 have submedian centromere, chromosome one has a median centromere and chromosome 6 has a subterminal centromere. The B chromosome has a nearly median centromere, the short arm has two chromomeres and the long arm has five chromomeres and may have originated from chromosome number six as a result of deletion and translocation. However these Bs do not pair with any of the A chromosomes during meiosis.

\section{Literature cited}

Barton, D. W. 1950. Pachytene morphology of the tomato chromosomes complement. Amer. J. Bot. 37: 639-643. 
Battaglia, E. 1964. Cytogenetics of B chromosomes. Caryologia 17: 245-299.

Jones, R. N. 1975. B chromosome system in flowering plants and animal species. The Int. Rev. of Cytol. 40: 1-100.

Lewis, H. 1951. The origin of supernumerary chromosomes in natural populations of Clarkia elegans. Evolution 5: 142-157.

Lima-de-Faria, A. 1952. Chromomere analysis of the chromosome complement of rye. Chromosoma 5: 1-68.

Magoon, M. L. and Shambulingappa, R. G. 1960. Karyomorphological studies in Sorghum ankolib var. Analib red, a Eu-Sorghum. Ind. J. Genet. and P1. Breed. 20: 166-177.

McClintock, B. 1929. Chromosome morphology in Zea mays. Science 69: 629-630.

Shastry, S. V. S., Ranga Rao, D. R. and Misra, R. N. 1960. Pachytene analysis in Oryza sativa. Ind. J. Genet. and Plant Breed. 20: 15-21.

Swanson, C. P. 1943. Secondary association of fragment chromosomes in the generative nucleus of Tradescantia and its bearing on their origin. Bot. Gaz. 105: 108-112.

Venkateswarlu, J. 1962. Some aspects of the study of pachytene chromosomes. Presidential address. Section of Botany 49th Indian Science Congress, Cuttack, India. pp. 113-132 (Part II).

Wu, J. P. and Pi, C. P. 1975. Accessory chromosomes in Sorghum nitidum Pers. Taiwania 20(2): 147-161.

- and - 1978. Pachytene morphology of Sorghum nitidum chromosome complement. Cytologia 43: 433-440. 